\title{
US court rules against releasing research data
}

ThE US Federal Court of Appeals has ruled that the raw data collected by university scientists in the course of federally-funded research programmes are not subject to the Freedom of Information Act, and need not therefore be disclosed to outside parties under the terms of the act.

This ruling was made last week on an FOIA application by a Boston-based medical group seeking to review the data gathered in a multi-university study of the treatment of diabetes mellitus, including the use of the oral hypoglycemic drugs. Largely based on the preliminary results of the study, which revealed that diabetics receiving the drug tolbutamide had a higher death-rate from cardio-vascular diseases than those receiving dietary or insulin treatment, the Food and Drug Administration recommended to physicians in 1970 that the use of oral hypoglycemics in the treatment of diabetes be carefully limited.

The appeals court's decision denies access to the raw data of the study by physicians contesting its conclusions. It therefore has implications for other areas in which the adequacy of data used for regulatory actions is challenged, and where the data has been collected by a non-government body.

Most applications for access to research data have so far come from public interest bodies such as the Washington-based Health Research Group, arguing that the public needs to be assured of the adequacy of safety and efficacy studies carried out on new drugs; one of the most controversial aspects of the proposed Drug Regulation Reform Act currently being debated by Congress, for example, is a move to make such information publicy available.

In contrast, however, the case on which the appeals court ruled last week had been brought by a group of physicians concerned that deficiencies in test procedures may have led to unwarranted restrictions of drugs which they claim to have used both safely and effectively, a claim supported by many of their patients.

The tests in question were part of a $\$ 7.3$ million study initiated in 1959 by a group of thirteen separate universities known as the Universities Group Diabetes Program, and funded by the National Institute of Arthritis, Metabolism and Digestive Diseases. Over a period of nine to eleven years, data was collected on more than 1,000 adult diabetes patients receiving treatment at university-affiliated medical schools, and forwarded quarterly to a co-ordinating centre at the University of Maryland for statistical analysis.

Following the controversy that surrounded the publication of preliminary results of the survey-and in particular criticisms of the methodology-the FDA contracted an independent review of the study by the Biometrics Society which, although expressing some reservations, concluded that the UGDP's evidence for the harmfulness of tolbutamide was "moderately strong".

But the critics were still not satisfied. And in September 1975 a FOIA action was sought by a group of 178 doctors known as the Committee on the Care of the Diabetic demanding access to the raw data of the UGDP study, which was defined as consisting of the forms transmitted to the co-ordinating centre and the computer tapes and/or programmes on the basis of which the data were analysed.

The appeals court rejected the application - which had earlier been turned down by a lower court--by a two to one verdict. It ruled that the act, which allows access to the records of federal agencies, should be interpreted literally, and that "only if a federal agency has created or obtained a record (or has a duty to obtain the record) in the course of doing its work, is there an agency record that can be demanded under FOIA."

The court said that research groups receiving federal grants do not thereby become government agencies, and that although an agency awarding a grant had a right of access to research data, it could not be compelled to exercise this right in order to generate agency records. The court also suggested that a decision that the UGDP raw data were agency records, and hence subject to the FOIA, would interfere with the autonomy of federal research grantees.

In a dissenting opinion, the third judge reviewing the case said that when taken together, three aspects of the research--that it was federally funded, that federal bodies had legal access to the data, and that the data was used for administrative decisionmaking-together implied that the materials were clearly agency records.

The applicants are seeking a rehearing, and if this is unsuccessful say they are prepared to refer the decision to the Supreme Court. And although the medical controversy over tolbutamide has calmed down in the past few years, further interest in the study has been generated by the conclusion, published in last week's Journal of the American Medical Association, that there is no evidence that the use of insulin or other substances designed to lower blood sugar in adults with mild diabetes will prevent progressive damage to blood vessels, the main cause of disabilities and death among diabetics.

David Dickson

\section{House stands firm on Clinch River fast breeder}

THE US House of Representatives has rejected a compromise formula offered by the Carter administration to end the long-standing dispute over the liquid metal fast breeder reactor project at Clinch River in Tennessee, making a presidential veto virtually inevitable.

The House rejected last Friday an amendment to the Department of Energy's authorisation bill which would have allowed President Carter to kill the Clinch River project, on which $\$ 800$ million has already been spent, replacing it with a longer-term design study of a larger fast breeder using the uranium/plutonium and ura- nium/thorium fuel cycles.

The amendment, which was defeated by 187 votes to 142 , had been offered by Representative Walter Flowers (D-Ala.), chairman of the science and technology committee's subcommittee on fossil and nuclear energy research. Two months ago the same amendment was narrowly defeated by the science and technology committee, despite the support of the chairman $\mathrm{Mr}$ Olin Teague, and indications from the administration that congressional plans to proceed with Clinch River would almost certainly be vetoed.

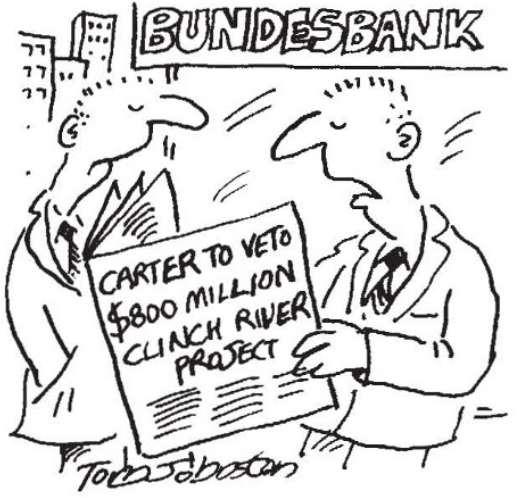

"Perhaps if he burns deutsch marks it would solve both his energy problems and our monetary problems!" 